\title{
Driving Impactful Research: A Conversation with Charles Dhanaraj
}

\author{
Jon Eckhardt (University of Wisconsin-Madison)
}

KEYWORDS: Entrepreneurship, Innovation, Research

Methods, Higher Education.

Charles Dhanaraj is the Executive Director of the Translational Research Center at Temple University's Fox School of Business and the H. F. Lenfest Professor of Strategy. He is an expert in strategic partnerships, global innovation, and emerging markets. $\mathrm{He}$ is a Fellow of the Academy of International Business (AIB), an honor bestowed on the top scholars in International Business. Professor Dhanaraj is on a mission to institutionalize closer relationships between business scholarship and the business community. In this edited conversation with EIX Editor Jon Eckhardt, Dhanaraj talks about how academic research can be made more useful to entrepreneurs and their businesses.

\section{Jon Eckhardt}

This is our second conversation on translational research in business schools. This term means many things to many people, but the core idea of translational research is about finding ways to connect research insights with practice and to connect business problems to the work of scholars. How do you define translational research in business?

\section{Charles Dhanaraj}

It is a two-way translation: One is translating what the business needs are to the academics and then the second is to translate what academic insights are to the business executives. It's not just about taking something written in top scholarly journals such as the Academy of Management Journal, or the Journal of Finance, then translating it for readability-although we need that too. It is more about helping researchers to get a grasp of the real pressing issues of the business, and getting practitioners more involved in guiding the direction of research.

\section{Jon Eckhardt}

What is your area of research?

\begin{abstract}
Charles Dhanaraj
My research is on the intersection of three broad themes: "Globalization, Innovation, and Collaboration." I worked on international joint ventures for my $\mathrm{PhD}$ dissertation, and so I started on the collaboration front. Then I moved on to looking at the globalization issues, including emerging markets. More recently I have been looking at global innovation where there is a lot of collaboration involved. How do we drive innovation in the global context in a collaborative manner? Those are the broad themes for my research.
\end{abstract}

\section{Discovering Translational Science Jon Eckhardt}

How did you become interested in translational science?

\section{Charles Dhanaraj}

The first time I heard about it was when I was at Indiana University. We had a National Science Foundation research grant. As we were looking through it, another colleague of mine from the medical school shared with me that IU was awarded a $\$ 70$ million grant from National Institutes of Health for a translational center in medicine. In fact, Indiana University built an entire building for translational medicine, and the $\mathrm{NIH}$ and Indiana University invested heavily. I saw the researchers, the business developers and the lawyers, all on one floor so that they started talking to each other. "From (laboratory) bench to (hospital) bed" was the motto.

That was the first time I saw it, but I didn't think about translational science so much until my last appointment in IMD, the quintessential executive ed school. We talked to close to 10,000 executives every year walking through the campus in Switzerland. My sense was that a lot of these executives have no clue about what the research world is like. We had expertise that even large 
companies could not get in house - in research, writing and alliance management. For me that was the "aha" moment. How is it that we have so much going on in the academic world, yet very little of that is being done or transferred to the executive side?

At the same time, I also saw a lot of executive issues. Each week, in the programs that we ran, I was meeting with different senior company executives, and we discovered a series of issues that were never addressed by researchers. To me, how it is that these two connections were not being made? I started thinking about it at that time, and it so happened that I bumped into the former dean of the Temple Business School. We talked about translational research, and he said, "Yeah, why don't you come and set something up here?" That's how it started.

\section{Are We Asking the Right Questions? Jon Eckhardt}

How is translational research part of your own scholarly work?

\section{Charles Dhanaraj}

It's funny you ask me that, because without knowing what translational research was, that was what I was doing. Part of my PhD training at Ivey included writing cases, which involved interviewing executives.

I was proud that my thesis won three different awards. But then, I met with executives at Eli Lilly after I gave them a short talk on my thesis, and one of them told me, "Well, it's an interesting work, but I really don't really care about that problem." I had done something on international joint venture mortality, or how long joint ventures survive. Basically, this executive was telling me, "We don't really care how long a joint venture survives. But, we really care about if it delivers value and if we are capturing it." That conversation was partly responsible for reorienting my own research, so to some extent this is what has driven the past 18 years of my research career.

\section{Jon Eckhardt}

Why were you presenting your dissertation to executives? That is unusual.

\section{Charles Dhanaraj}

After my thesis on international joint ventures, I joined Indiana University in 2000 and read about a joint venture of Eli Lilly in India. Eli Lilly was just about 20 minutes from my campus, so I did some few blind calls. I reached one of the executives who said, "Oh, sure. We would be happy to talk to you about it." That became a case writing project, then that got us into a National Science Foundation research grant on alliances. In fact, I would say a lot of my learning about alliances happened working with Lilly. It was during this process I got this opportunity. That case that I wrote in 2005, "Eli Lilly in India: Rethinking Joint Venture Strategy," is still one of the best-selling cases in Ivey.

\section{Research and its ROI Jon Eckhardt}

Sharing insights from academically inspired research is one way that business schools can connect to practice. In your example, you learned from the businesses in addition to sharing what you had discovered. Let's return to the topic of translational science. Why should business schools care about it?

\section{Charles Dhanaraj}

As a professional school, we care about impact. Consider that a typical research-driven business school spends a considerable amount of its resources on research. Probably more if you factor in how we pay our faculty and giving them time off for research. That's much more than any of the industries that we know of, right?

Then the question comes: what is the ROI on this investment? We don't have much to show for this investment. For example, how many people read an article in a top journal? Maybe if you come up with a fantastic idea about 100 or 200 people will read it. Maybe 1,000 if you do some outstanding article, but the majority of executives will still have no clue to what this research is all about. Very little of what we are really doing gets translated into actual insight to the executives. In the process, we lose a lot. That's why l'm focusing on translational science.

\section{Jon Eckhardt}

You've referred to medical schools as examples of translational science when describing your time at IU. How do you respond to the view that translational science makes sense in medical schools when you're trying to extend human life, but it doesn't make sense in business because business is a socially constructed endeavor? 


\section{Charles Dhanaraj}

You can flip that question into another question saying, "Does it matter if an executive does not make the right decision? Because if he or she does not make the right decision, thousands of people lose their jobs and lose their livelihoods." This is fundamental. What do we teach in business schools? It's to make good decisions, so that they can run businesses well. Not just for their own profit, but for their communities. That's what our whole research is all about: helping management make better, data-driven decisions. Don't you think we affect lives? To me that's almost life and death.

\section{Enhancing Business Performance Jon Eckhardt}

To push this a little bit further. What makes you think that we can use science to enhance the performance of business? For example, it takes several years to produce and publish a scientific piece of work in business, and during that period of time an executive may have to make 2,000 decisions. Is it even possible to use science that way?

\section{Charles Dhanaraj}

Science moves incrementally, in the sense that you don't come up with one big insight....and bingo, the whole world changes. Take for example Netflix. The whole entertainment industry is being re-crafted, and now only one Blockbuster store is left. Reed Hastings had a great idea-but I think it was the continuous learning and improvising that got them where they are. Academic institutions can learn from this. It's not about waiting for 10 years and then coming up with the one final product, and then we deliver it to the industry and then we sign off. It's about constantly working with them to move the frontiers slowly but steadily.

\section{Jon Eckhardt}

Can you give us a specific example of translational science working, or it is just so rare at the moment that we don't really have enough good examples of that right now?

\section{Charles Dhanaraj}

I think we are seeing great examples in the digital transformation arena. You can find a good level of academic and industry engagement. For example, researchers who are working with the industry closely are able to come up with better insights
If you look at any of the papers that are coming out in Harvard Business Review or McKinsey Quarterly, these are papers written by researchers willing to step outside of the ivory tower. They are getting into the field, talking to executives, and doing great work. Partly it is being forced upon us, since the pace of technology is so fast that we cannot understand it unless we get out into the field and co-create new knowledge with the practitioners. We desperately need more research focused on issues that matter.

\section{Translational Research at Temple Jon Eckhardt}

Let's switch gears for a little bit now and talk about what you're doing at Temple University. Where did the idea for the Translational Research Center come from at Temple? What is the vision, and where is the center is headed?

\section{Charles Dhanaraj}

I look at it as a double-edged program. One is working internally within the school to move our research to a higher impact zone; the other is working externally in collaboration with like-minded people across the academy to come up with more data-driven insights on impact.

We use a star model of impact, where we highlight five critical stakeholders for a business school: students, academia, business, policy and community. Research needs to address them all-not that every researcher has to be speaking to all these five stakeholders, but as an institution we should be able to speak to them all.

Like most business schools, we focus on academic journals. A lot of what gets rewarded in a researchdriven business school is how we are able to influence fellow academics, right? But it is also important to measure how we influence the other stakeholders in the star: students, the business, community and policy. The challenge I've put for myself and for the center is: can we come up with better metrics to measure the multisided impact? If impact is multidimensional, can we find ways to create multidimensional measures of impact? That's one of the challenges to go forward.

\section{Jon Eckhardt}

How is the center currently funded?

\section{Charles Dhanaraj}


Right now, we are funding it from the school's funds, so that's the daring part from the school's Interim Dean Ronald Anderson. My hope is that in a year or two this center will secure the support of innovative leaders in industry.

\section{Jon Eckhardt}

What are Interim Dean Anderson's goals for the center? The same as we've been talking about, or anything different?

\section{Charles Dhanaraj}

I think it's about disruption in two areas. One is how we disseminate knowledge, or the way we teach, from the physical classrooms to online learning and hybrid modules. Two is how we produce knowledge, or what I call "how the research enterprise operates." I think on those two fronts we have a pretty good chance that we can disrupt the industry and perhaps lead the industry.

\section{Reaching Out to Editors Jon Eckhardt}

Let's talk about some of the specific initiatives of the center. Can you tell us about the editors' conference that was hosted by the center? Who was there, and what happened at the conference?

\section{Charles Dhanaraj}

In March 2018, we had the Editors Summit. We need top journal ideas that are thought-provoking, ideas that are fundamentally shifting the way we think. The idea was to bring these multi-disciplinary editors together and ask them, "How can we drive real impact?" This was the first time editors from multiple disciplines-marketing, finance, accounting, MIS, Strategy, OB-were in one room. We had nine editors from the top business journals from all the major disciplines.

We had three big takeaways. One, journals and editors want to be impactful-but they can only publish what is submitted to them. We need to spur more faculty engaging in high-impact research. Journals can be creative in introducing new processes to motivate it, but it is the business schools that have to create the incentives for faculty to build up such work.

Two, we need the academic community to be more open-for example, we need peer reviewers who can be open and receptive to new ways of knowing, who encourage risk taking and are more open to innovative research. Three, we need to focus a lot more on what happens after the research is published. It was very clear that top journal publication should not be an end, but the beginning. We need to focus a lot more on how to help faculty take the research insights into the classroom and also lead in its implementation.

\section{Listening to Practitioners Jon Eckhardt}

You mentioned the deans and the editors, what do the practitioners say? The CEOs?

\section{Charles Dhanaraj}

That's our big client, right? For many senior business leaders, business schools are just labor markets that supply graduates for their employment. They don't seem to look at us as "knowledge markets" that supply expertise. I also know that a lot of thoughtful executives want to know, "What's the latest and most interesting stuff?" but academics have not harnessed it well. At the editors summit we had Bob Patel, CEO of LyondellBasell, a company with $\$ 35$ billion in revenue, sharing ideas on how academics could help. He said, "I have three big issues. How do I move from a smokestack to digital? How do I deal with the changing talent requirement that I have? How do I deal with sustainability, given that I'm in the chemical industry?" I am sure there are many more issues that are hot from the vantage point of industry leaders. Getting academics to engage with this group, and distilling them into critical research programs, is what we need to do. That's where we are hoping we can make a difference.

\section{The 'Netflix of Academia' Jon Eckhardt}

What else are you planning?

\section{Charles Dhanaraj}

We are working on three areas: increasing engagement with industry, facilitating translational research and enabling effective communications.

For increasing engagement, we are pushing in two directions: increasing sponsored research with industry participation; and getting faculty to write cases on emerging challenges for businesses. We have a fairly large group of faculty members drawn from practice, with several decades of business experience and rich networks. We are engaging with them for advancing the 
translational scholarship. We also have an EDBA (Executive Doctorate in Business Administration) program, where we are specifically building up our applied research areas.

For facilitating translational research, we are partnering with the centers in the business schools. The centers are typically built around a very specific theme, like innovation or digital, and can draw faculty members from multiple disciplines. These centers can be a powerful platform for connecting research faculty and business executives around those specific themes. Imagine a Center on Corporate Governance, working with faculty in accounting, finance, legal studies and strategy and with companies like Vanguard and others. They will be able to create excellent research, and disseminate it with the partner companies and also be a hotbed for program innovation.

For enabling communication and advancing media, we try to work with the marketing and communication folks. It will take some time to get faculty comfortable with the new media, and getting them oriented to podcasts and webcasts, but surely this is a way we want to go. A big dream of mine is to see if we can be the "Netflix of Academia"- how do we funnel the right knowledge to the right executive at the right time? For all practical purposes, today, we just throw out our insights through journals or media and we hope that people are reading it. Closing that loop, and creating a feedback from the readers, can create a demand-driven knowledge creation system!

\section{Jon Eckhardt}

Do you have any parting thoughts?

\section{Charles Dhanaraj}

Thank you for this great opportunity. Fundamentally, business school is a professional school. The moment we stop being an impactful institution, we jeopardize our long-term future. It's incumbent on us to focus on impact, and translational science is a way to that goal.

Additional Search Terms: relevant research, working with colleges and universities, best practices, entrepreneurship schools, business schools 